\title{
Study of Morphological Variations of Suprascapular Notch
}

\author{
Dr. Nagaraj S ${ }^{1}$, Dr. M. Krishnaiah ${ }^{2}$, Praveen Kumar $\mathbf{M}^{3}$, Dr. Anil R Sherke ${ }^{4}$ \\ 1,2,3,4 Department of Anatomy, Kamineni Institute of Medical Sciences, Narketpally
}

Abstract: The suprascapular notch is located medial to the root of coracoid process of the scapula. Suprascapular notch presents various types, among which narrowed one looks like V shaped and is vulnerable for suprascapular nerve entrapment syndrome. Hence we attempted to define various varieties of shapes of suprascapular notch in 104 dried scapulae and compared with the previous studies.

Keywords: Suprascapular notch, suprascapular foramen, suprascapular nerve entrapment syndrome

\section{Introduction:}

Scapula also known as the shoulder blade is triangular in shape and is the fulcrum and basis of all the motions of the humerus. Its peculiar shape has always been a point of attraction to many Anatomists. The superior margin of the scapula is thin and sharp and is the shortest of the three. It is interrupted by the scapular notch, which lies very close to the medial side of the coracoid process. This notch is bridged by the superior transverse scapular ligament, thus converting it into a foramen. The suprascapular nerve, the solitary branch from the upper trunk of the brachial plexus passes through the suprascapular foramen and supplies supraspinatus descends lateral to the scapular spine with suprascapular vessels and supplies infraspinatus and gives a twig to the shoulder joint. ${ }^{1}$

Cadaveric studies reveal that the suprascapular notch may be either U shaped or V shaped, and some physicians believe that this anatomic variation may be related to an individual's predisposition to SSN entrapment at this level. ${ }^{2}$ Hence, the study of variations in the shape of suprascapular notch become important.

\section{Objective}

To observe the variations in suprascapular notch, because some particular type of such variations are a predisposing factor for suprascapular nerve entrapment syndrome.

\section{Materials}

104 dried scapulae from Deccan Medical College and KIMS, Narketpally were studied. Scapulae with deformed superior border were excluded from the study.

\section{Methods}

These scapulae were studied for different shapes of suprascapular notch, its absence and ossification of the suprascapular ligament. This system classifies the suprascapular notch into two distinct types, namely the Ushaped suprascapular notch, defined as having approximately parallel sides with a rounded base, and a V-shaped suprascapular notch, defined as having medial and lateral sides which converge toward a narrow base. ${ }^{3}$
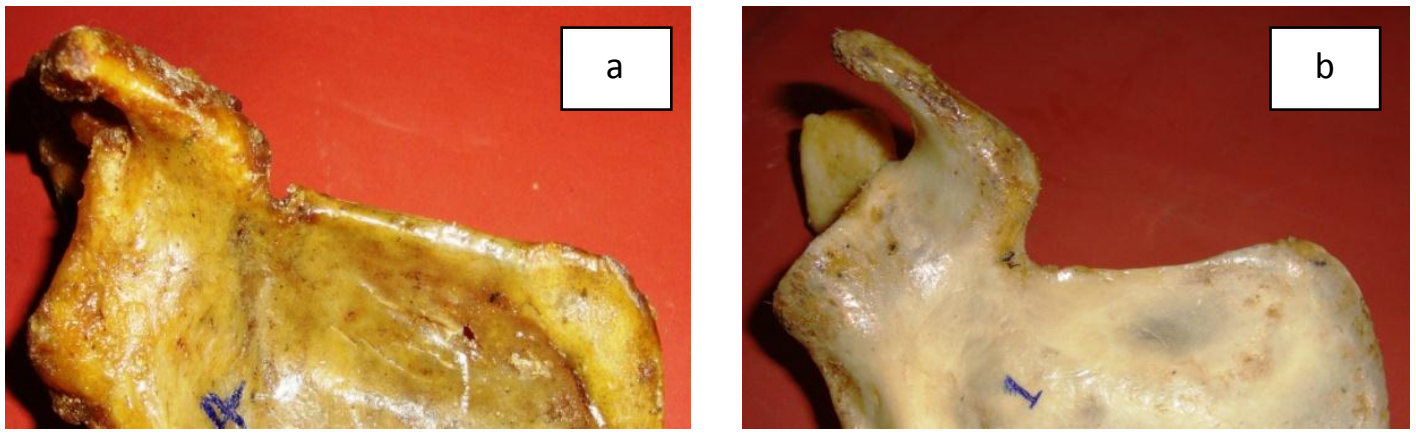

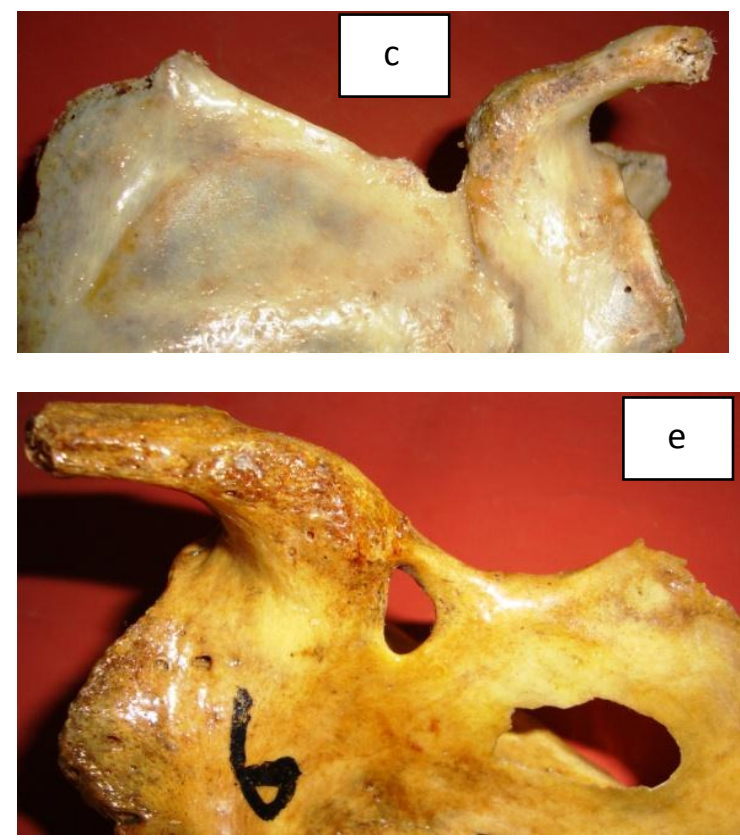

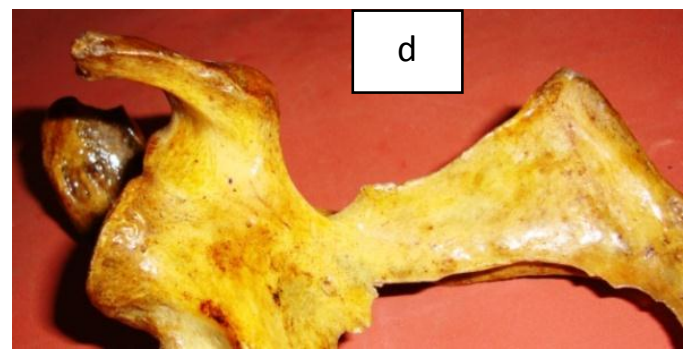

Fig1 Showing different shapes of suprascaplar notches
a) J shape
b) Absence
c) U shape
d) V shape

e) Ossified suprascapular ligament

\section{Results}

In the present study of 104dried scapulae (as shown in Table1) we found 45 scapulae with $\mathbf{J}$ shaped suprascapular notch, $28 \mathrm{u}$ shaped suprascapular notch and $2 \mathrm{v}$ shaped suprascapular notch. There were 3 scapulae with indentation at the place of suprascapular notch while 24 scapulae showed the absence of suprascapular notch. We found 3 scapulae with ossification of superior transverse scapular ligament thus converting suprascapular notch into foramen

Table1 showing the different varieties of suprascapular notch- their number and percentage $\mathrm{N}=104$

\begin{tabular}{|l|l|l|}
\hline Shape f Notch & Number of Scapulae & Percentage (\%) \\
\hline J shape & 45 & 43.26 \\
\hline U shape & 28 & 26.92 \\
\hline V shape & 2 & 1.92 \\
\hline Indentation & 3 & 2.88 \\
\hline Absent & 24 & 23 \\
\hline Ossified suprascapular Ligament & 3 & 2.88 \\
\hline
\end{tabular}

\section{Discussion}

The shape of the suprascapular notch was described and classified by various authors in the past. They are $\mathrm{J}$ shaped, U shaped V shaped, indentation at the suprascapular notch, absence of notch, and ossification of suprascapular ligament. The results of the present study compared with those of previous studies are tabulated as below.

Table 2 showing comparison of percentage of distribution of suprascapular notch of present study to that of previous studies

\begin{tabular}{|c|c|c|c|c|c|c|}
\hline \multirow[b]{2}{*}{ Shape } & \multicolumn{5}{|c|}{ Previous studies (\%) } & Present study \\
\hline & $\begin{array}{l}\text { Iqbal et al }{ }^{4} \\
2010\end{array}$ & $\begin{array}{l}\text { Sinkeet et al }{ }^{5} \\
2010\end{array}$ & $\begin{array}{l}\text { Polguj et al }{ }^{6} \\
2011\end{array}$ & $\begin{array}{l}\text { Soni et al }{ }^{7} \\
2012\end{array}$ & Vasudha et al ${ }^{8} 2013$ & 2014 \\
\hline J shape & 22 & - & - & 27 & 19.13 & 43.26 \\
\hline Symmetrical & - & 29 & 2.3 & - & 34.7 & - \\
\hline U shape & 13.2 & 21(shallow) & 24.4 (deep) & 58 & $\begin{array}{l}6.08 \text { (shallow) } \\
6.08 \text { (deep) }\end{array}$ & 26.92 \\
\hline V shape & 20 & 5.18 & - & 7 & - & 1.92 \\
\hline Indentation & 33.5 & - & - & 3 & 7.82 & 2.88 \\
\hline Absent & 22.5 & 2.12 & - & 2 & 6.08 & 23 \\
\hline Ossified SSL & - & - & - & 14 & 6 & 2.88 \\
\hline Wide notch & - & - & 57.7 & - & 6.95 & - \\
\hline Hockey stick & - & 22 & - & - & 5.21 & - \\
\hline
\end{tabular}




\begin{tabular}{|l|l|l|l|l|l|l|}
\hline shape & & & & & & \\
\hline Groove & - & - & - & - & 0.88 & - \\
\hline
\end{tabular}

Among the total number, the $\mathrm{J}$ shaped suprascapular notch was maximum $(43.26 \%)$. The least number was $\mathrm{V}$ shaped i.e. $1.92 \%$. This finding of least V shaped being least common correlated with Soni et al and Iqbal et al. This study shows U shaped suprascapular notch as $26.92 \%$. In $23 \%$ of scapulae suprascapular notch was absent. In $2.88 \%$ of scapulae an indentation was observed at the suprascapular notch. We also found completely ossified suprascapular ligament converting the notch into foramen in $2.88 \%$ scapulae. Dunkelgrun et al stated that ' $U$ ' shaped notches had a larger area than the ' $\mathrm{V}$ ' shaped notches, leading to the assumption that a ' $\mathrm{V}$ ' shaped notch is more likely to be connected with nerve entrapment. ${ }^{9}$

\section{Conclusion}

The study of variations of suprascapular notch and ossification of suprascapular ligament is important to understand suprascapular nerve entrapment syndrome. Hence, our study attempted to define the various varieties of the suprascapular notch. This study is useful for anatomists, orthopaedicians, radiologists and neurosurgeons for a better diagnosis and management of the entrapment syndrome.

\section{References}

[1]. R.M.H Mc Minn, Last's Anatomy., $9^{\text {th }}$ ed. UK edition: Churchill Livingstone, 2009. P.68

[2]. Suprascapular Neuropathy by Thomas H Trojian et al. Available from: http://emedicine.medscape.com/article/92672overview\#a0106 Accessed May 30th, 2014.

[3]. Natsis K, Totlis T, Tsikaras P, Appell H G Skandalakis P, Koebke J. Proposal for classification of SSN: a study on 423 dried scapulae. Clin Anat 2007; 20:135-39.

[4]. Iqbal K, Iqbal R, Khan SG. Anatomical variations in shape of suprascapular notch of scapula; J Morphol.Sci. 2010,27(1): 1-2.

[5]. Sinkeet SR. The suprascapular notch: its morphology and distance from the glenoid cavity in a Kenyan population; Folia Morphol, 2010; 69:241-45.

[6]. Polguj M. Correlation between Morphometry of the SSN and anthropometric measurements of the scapula. Folia Morphol,2011; $70,109-15$.

[7]. Soni G, Malik VS, Shukla L, Chabbra S, Gaur N. Morphometric Analysis of the Suprascapular Notch. The Internet Journal of Biological Anthropology. 2012; 5(1): DOI: 10.5580/2b19

[8]. Vasudha TK, Ashwija Shetty, Sadashivana Gowd, Rajasekhar SSSN . Morphological study on suprascapular notch and superior transverse scapular ligaments in human scapulae. Int J Med Res Health Sci. 2013;2(4): 793-798

[9]. Dunkelgrun M, Lesaka K, Park SS, Kummer FJ, Zuckker-man JD. Interobserver reliability and intraobserver reproducibility in suprascapular notch typing. Bull Hosp Joint Dis.2003; 61: 118-22. 